\title{
BMP-2 inhibits lung metastasis of osteosarcoma: an early investigation using an orthotopic model
}

This article was published in the following Dove Press journal:

OncoTargets and Therapy

\author{
Qisheng Xiong ${ }^{1,2}$ \\ Xuesong Wang ${ }^{3}$ \\ Lizhen Wang ${ }^{1,2}$ \\ Yan Huang ${ }^{1,2}$ \\ Xiaodong $\operatorname{Tian}^{3}$ \\ Yubo Fan ${ }^{1,2}$ \\ Chia-Ying $\operatorname{Lin}^{1,2,4,5}$
}

'School of Biological Science and Medical Engineering, Beihang University, Beijing, China; ${ }^{2}$ Beijing

Advanced Innovation Center for Biomedical Engineering, Beihang University, Beijing, China; ${ }^{3}$ Spine Department, The No 2 Affiliated Hospital of Qingdao University, Qingdao, China; ${ }^{4}$ Department of Orthopaedic Surgery, University of Cincinnati Academic Health Center, Cincinnati, OH, USA; ${ }^{5}$ Department of Biomedical Engineering, University of Cincinnati, Cincinnati, OH, USA
Correspondence: Chia-Ying Lin Department of Orthopaedic Surgery, University of Cincinnati Academic Health Center, 23I Albert Sabin Way, Cincinnati, OH 45267-02I2, USA

$\mathrm{Tel}+\mathrm{I} 5 \mathrm{I} 355884 \mid 2$

$\mathrm{Fax}+\mathrm{I} 5135582220$

Email chia-ying.lin@uc.edu
Background: Bone morphogenetic proteins (BMPs), members of the TGF- $\beta$ superfamily, are known to regulate cell proliferation, differentiation, apoptosis, chemotaxis, and angiogenesis. BMPs also participate in the development of most tissues and organs in vertebrates. Recombinant human (rh) BMPs, such as rhBMP-2, rhBMP-4, and rhBMP-7, have been recently approved to augment spinal fusion and recalcitrant long-bone non-unions because of their equivalent or superior efficacy to autogenous bone graft in enhancing bony fusion. Nonetheless, the use of BMPs is contraindicated in surgery for bone tumors because of concerns that this anabolic growth factor may cause tumor proliferation. However, we have repeatedly reported that BMP-2 is effective in inducing osteogenic differentiation of a subpopulation of osteosarcoma (OSA) cells that acquire stem cell attributes and are capable of reconstituting tumor masses, which in turn suppress the malignancy of the bone tumor.

Methods: $3 \times 10^{5} / 20 \mu \mathrm{L}$ human OSA $143 \mathrm{~B}$ cells were inoculated into 5-6 weeks old BABL/c nude mice to establish orthotopic OSA. X-ray device was used to monitor the developed tumors in animals. Necropsy was performed and the pathology of lung metastasis were tested by Haemotoxylin and Eosin. Moreover, bone formation induced by rhBMP-2 was investigated through micro-computed tomography. In addition, immunohistochemistry staining was used to evaluate the tumorigenicity and growth of OSA cells after rhBMP-2 treatment.

Results: In the present study, we established an orthotopic model of OSA by inoculating 143B cells into $\mathrm{BABL} / \mathrm{c}$ mice, which resulted in a tumor occurrence rate of $100 \%$. Following the treatment with rhBMP-2, lung metastasis, which contributes to poor prognosis, was significantly restricted, indicating an additional aspect of rhBMP-2 to suppress expansion of OSA. Concurrently, our micro-computed tomography and radiographic analyses showed that rhBMP-2 reduced the invasion of tumor cells into adjacent bone tissue, which in turn helped to preserve the integrity of the affected bone tissue. Finally, the growth of Ki-67-positive cells and those cells that express high levels of aldehyde dehydrogenase $\left(\mathrm{ALDH}^{\mathrm{br}}\right)$ was found to be inhibited in the developed tumors. Conclusion: On the basis of these results, we conclude that rhBMP-2 can impede the malignancy of OSA by reducing lung metastasis of the tumor. Induction of the tumor cells by rhBMP-2 also helps to preserve the impaired skeleton. These results imply that BMP-2 or BMP-2-mimetic drugs, if properly combined with traditional therapies, may provide a new therapeutic option for the treatment of OSA.

Keywords: osteosarcoma, recombinant human bone morphogenetic protein-2, lung metastasis, orthotopic tumor model, cancer stem cell

\section{Introduction}

Osteosarcoma (OSA) is one of the most malignant tumors particularly occurring in children, adolescents, and young adults. ${ }^{1-6}$ Over $60 \%$ of patients with OSA are diagnosed between the age of 10-20 years old, ${ }^{7}$ with tumor present in the spine and limbs such as distal femur, proximal tibia, and proximal humerus. ${ }^{5}$ OSA in elderly patients, on the other hand, is often 
linked to other causes such as Paget's disease or some other bone lesions. ${ }^{5,7,8}$ Over the past few decades, the combined use of chemotherapeutics with aggressive surgery has improved the long-term survival rates of patients with OSA to around 65\%. ${ }^{9,10}$ However, approximately $10 \%-20 \%$ of patients with OSA have metastases at the initial diagnosis. When the tumor metastasizes to the lung, almost all patients succumb to death, unless the pulmonary metastasis can be resected completely. ${ }^{11}$ Clinically, metastatic OSA also poses a great challenge for its treatment. Signatures of genes that regulate chemoresistance are often expressed in the metastatic tumor. ${ }^{12,13}$ Furthermore, conventional chemotherapy is always accompanied with toxic and adverse effects that compromise the quality of life of patients. ${ }^{14-17}$

Reconstruction of impaired skeleton affected by OSA presents an additional challenge. Surgical management of symptomatic OSA typically involves resection of the tumor in conjunction with bone stabilization. Such stabilization presently involves placement of instrumentation to internally fixate the affected segments. Instrumentation, however, will eventually fail unless a bony fusion occurs. Unfortunately, the patients with OSA typically also undergo chemo- and radiation therapies that negatively affect such fusion. Even without adjuvant treatments, bone regeneration can still be difficult to achieve with standard fusion techniques. All these hurdles have urged new investigations to explore new alternatives to treat OSA.

Bone morphogenetic proteins (BMPs), a group of cytokines belonging to the TGF- $\beta$ superfamily, play important roles in bone tissue formation and remodeling. ${ }^{18-20}$ BMPs have been known to regulate cell proliferation, apoptosis, differentiation, chemotaxis, and angiogenesis and induce bone and cartilage formation in vivo and in vitro. ${ }^{18,21-24}$ However, the roles of BMPs in tumorous tissues are often contradictory. BMP-2 has been shown to stimulate the growth of pancreatic carcinoma and lung carcinoma. ${ }^{25,26}$ On the other hand, BMP-2 clearly inhibits the growth of tumor cells including breast cancer, ${ }^{27,28}$ myeloma, ${ }^{29}$ gastric cancer, ${ }^{30}$ colon cancer, ${ }^{31}$ brain tumor, ${ }^{32}$ and prostate cancer in the absence of androgen. ${ }^{33,34}$ Overexpression of BMP-2 in rat OSA UMR106 cells inhibits proliferation and results in osteoblastic transdifferentiation. ${ }^{35}$ Geng et al have shown that Coleusin factor inhibits OSA proliferation through BMP-2 upregulation and subsequent osteoblastic differentiation. ${ }^{36}$ Wang et al reported that BMP-2 causes inhibition of tumor-inducing gene expression and upregulation of differentiation markers, which in turn inhibit the tumorigenicity of high aldehyde dehydrogenase expressed $\left(\mathrm{ALDH}^{\mathrm{br}}\right)$ cells derived from human OSA OS99-1 cells. ${ }^{37}$ Recombinant human (rh) BMP-2 has also been reported to inhibit tumor growth and induce bone formation in human renal cell carcinoma cells, ${ }^{38}$ which often invade spinal columns due to the close vicinity.
The exogenous application of BMP-2 to the surgical site following tumor excision does not increase the risk of local recurrence. ${ }^{39}$ Furthermore, a recent study by Gill et al using xenografted OSA indicated that the addition of BMP-2 did not increase the risk of lung metastasis. ${ }^{40}$ However, the major limitation of all the above studies was that the observations were mainly based on the subcutaneous model system. It will therefore be more clinically beneficial and relevant to conduct the evaluation with an orthotopic model to further improve the efficacy of BMP-2 in the treatment of OSA.

In the present study, an orthotopic OSA model with a high lung metastasis rate was established. The affected animals expressed several clinical symptoms similar to those observed in human patients. ${ }^{41}$ We then used the model to further assess the effect of BMP-2 on lung metastasis and how it can be used to treat bone erosion symptoms.

\section{Materials and methods Cell culture and inoculation of OSA cells}

Human OSA 143B cell lines were purchased from the American Type Culture Collection. Cells were cultured in minimum essential medium (Hyclone) supplemented with 10\% FBS (Gibco) in a humidified atmosphere of $5 \% \mathrm{CO}_{2}$ in air at $37^{\circ} \mathrm{C}$ and used during the log phase of growth. A total of $3 \times 10^{5} / 20 \mu \mathrm{L}$ human OSA 143B cells were inoculated into 5- to 6-week-old $\mathrm{BABL} / \mathrm{c}$ nude mice (SLRC Laboratory Animal) to establish orthotopic OSA. The animals were anesthetized with Zoletil 50 (Virbac), and operative fields were prepared with iodine and $75 \%$ alcohol. OSA cells were directly injected into the right side of the proximal tibia. All the studies were approved and performed according to the protocols of Institutional Animal Care and Use Committee of Beihang University.

\section{OSA models treated with rhBMP-2}

$\mathrm{BABL} / \mathrm{c}$ nude mice with orthotopic OSA were divided into four groups at random: Group A ( $\mathrm{n}=14,17.76 \pm 0.48 \mathrm{~g})$; Group B $(\mathrm{n}=14,17.81 \pm 0.65 \mathrm{~g})$; Group C $(\mathrm{n}=14,17.69 \pm 0.55 \mathrm{~g})$; and Group D ( $\mathrm{n}=15,17.97 \pm 0.56 \mathrm{~g})$. For the rhBMP-2/collagen gel preparation, $25 \mu \mathrm{L}$ of injectable collagen gel was mixed with $2.5 \mu \mathrm{L}$ of the same reconstituted solution containing $2.5 \mu \mathrm{g}$ of rhBMP-2 (\#355-BM; R\&D Systems). The compound was then injected into the animals of Groups $C$ and D 14 days after tumor cell inoculation of $143 \mathrm{~B}$ cells with a $0.3 \mathrm{~mm}$ ( 25 -gauge) needle at the orthotopic sites. The animals were anesthetized as described before. All the tumor-bearing mice were sacrificed after 42 or 56 days of tumor cell inoculation. The animals identified to have critical conditions before this period were excluded early from the study and humanely sacrificed. 


\section{Radiographic track of the developed OSA}

A portable X-ray device (BJI-G; HSCreate) was used to monitor the developed tumors in animals. The entire affected limbs were monitored every 7 days with animals under anesthesia as aforementioned.

\section{Lung metastasis assay}

After the animals were sacrificed, their lung tissues were collected and stained with hematoxylin and eosin. Necropsy was performed, and the pathology of lung metastasis was graded according to the number and size of the identified tumor nodules in the lung tissues. Samples were categorized according to the following scores: $0=$ relatively normal where no tumor cell aggregation is present in the pulmonary tissue; $1=$ mild where tumor cell aggregation is $<25 \%$ coverage; $2=$ moderate indicating the aggregation region accounts for $25 \%-50 \% ; 3=$ moderate to marked where the aggregation coverage extends to $50 \%-75 \%$; $4=$ marked where $>75 \%$ aggregation is distributed in the affected lung tissue.

\section{Micro-computed tomography to scan bone tissue}

Micro-computed tomography was performed postmortem by using the SkyScan1176 system (Bruker microCT) at 42 days (Groups $A$ and $C$ ) and 56 days (Groups B and D) after cell inoculation. Scans were performed at the tibiae using a $0.5 \mathrm{~mm}$ aluminum filter at $50 \mathrm{kV}$ voltage and $500 \mu \mathrm{A}$ current. Images were then reconstructed using Mimics ${ }^{\circledR} 17.0$ (Materialise). Bone mineral content (BMC), volumetric bone mineral density (vBMD), bone volume (BV), and bone surface (BS) were calculated, and the region of interest was 400 slices from the growth plate to the distal tibia.

\section{Immunohistochemical staining}

Cells expressing a high level of $\mathrm{ALDH}^{\mathrm{br}}$ and $\mathrm{Ki}-67$ were stained. Briefly, formalin-fixed paraffin-embedded sections of tumor samples were stained with mouse anti-Ki-67 antibody (sc-23900; Santa Cruz Biotechnology, Inc.) and mouse anti-ALDH antibody (sc-166362; Santa Cruz Biotechnology, Inc.) using standard procedures. Immunofluorescent staining was performed as previously described. ${ }^{42}$

\section{Statistical analysis}

Data were expressed as mean \pm SD. Statistically significant differences were determined by two-tailed Student's $t$-test using SPSS 22 software (IBM, Armonk, NY, USA) with a significant level at $P<0.05$.

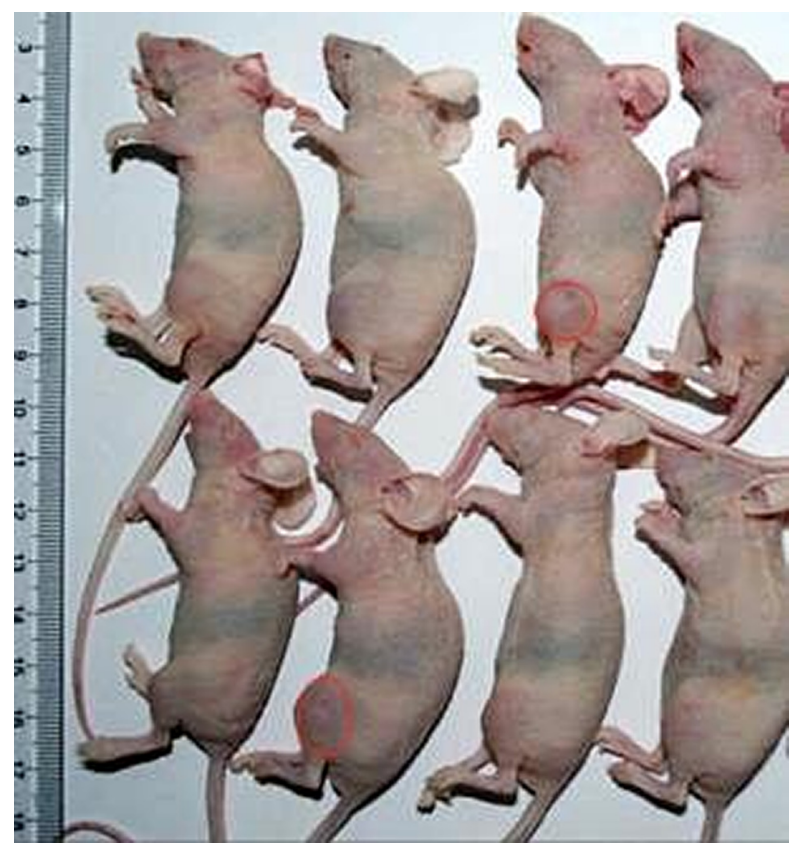

Figure I The developed mouse model of osteosarcoma (orthotopic). Notes: 143B human osteosarcoma cells were inoculated into the proximal tibia of into 5-6 weeks old BABL/c nude mice. The tumor (red circle) occurrence rate reached $100 \%$ I 4 days after the tumor cell injection.

\section{Results}

\section{An orthotopic OSA model with high tumor incidence}

Fourteen days after implantation with 143B human OSA cells into the tibia, eight mice were randomly photographed. The results confirmed that the tumor growth rate had reached almost 100\% (Figure 1). Radiographic evidence indicated osteolytic epiphyses, with the presence of the Codman triangle, which is a primary characteristic of OSA observed in bone tissue (Figure 2A). Further, erosion of the affected skeleton deteriorated over time (Figure 2B). Skeleton of the affected limbs was severely eroded, and the affected soft tissue formed few lumps with calcification shadows 28 days later (Figure 2C). With progression in time, the proximal tibia tissue was completely impaired, and the adjacent soft lumps continued to grow until 42 days (Figure 2D). In addition, the first spontaneous death occurred in Group B (untreated) after 37 days of inoculation of tumor cells.

\section{Restriction of lung metastasis by rhBMP-2}

Metastatic nodules were observed in the sections of lung tissues and presented in different numbers and sizes. Large tumor nodules were identified to colonize the lung tissue of $\mathrm{BABL} / \mathrm{c}$ mice without rhBMP-2 treatment at 42 days (Figure 3A). Eventually, the entire organ was infiltrated by the tumor cells as shown in Figure 3B. Although lung 
Day 13

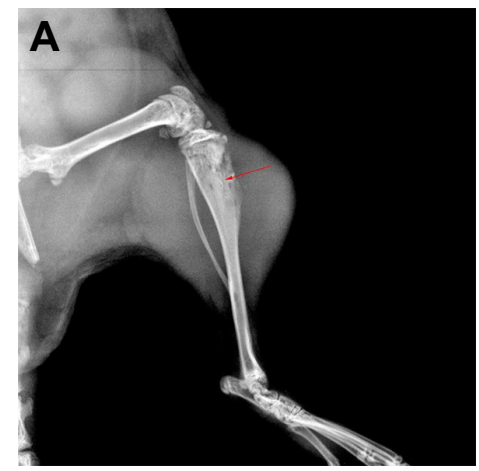

Day 28

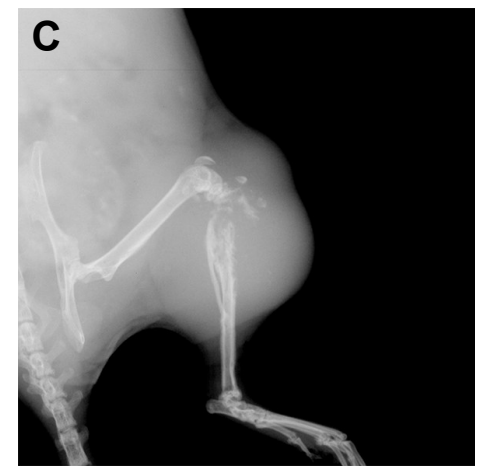

Day 20

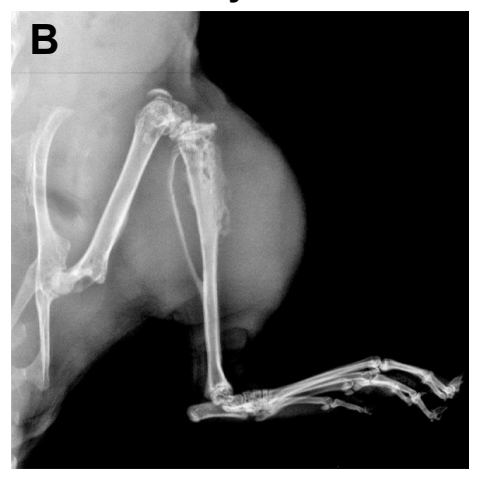

Day 42

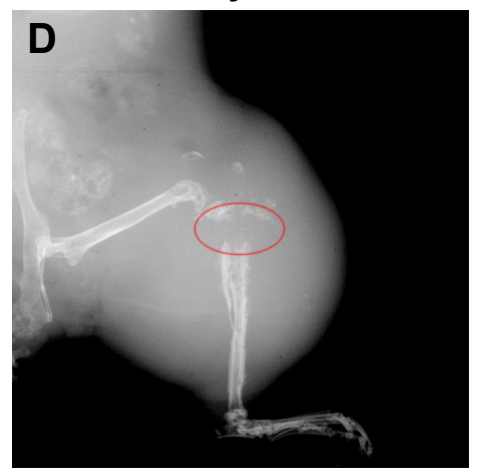

Figure 2 Radiographs indicated the impaired proximal tibias by OSA.

Notes: (A) Thirteen days after the inoculation of tumor cells, tumor lesion in the injected proximal tibia was noticed, with osteolysis indicated by the Codman triangle (red arrow). Erosion of the affected skeleton deteriorated over time (B), and the surrounding soft tissue started to form lumps with calcification shadows 28 days postinnocuation (C). (D) The tumor lesion became completely destructive at the injected tibia at 42 days.

Abbreviation: OSA, osteosarcoma.

metastasis also occurred in the groups treated with rhBMP-2, the tumor nodules were much smaller and confined without extensive spread (Figure 3C and D).

To evaluate whether rhBMP-2 restricts the development of metastatic tumors in the lung, the number and size of nodules identified in the tissue sections were measured (coverage of tumor cell aggregation) to assess the efficacy. Metastasis grading (Table 1) indicated no obvious difference between the treated and untreated groups (Groups A and C) at 42 days, with grades of $2.4 \pm 1.14(n=5)$ and $2.0 \pm 1.0(n=5)$, respectively. However, metastasis was highly inhibited at 56 days in the group receiving rhBMP-2 (Group D), with a grade of $2.2 \pm 1.48(n=5)$, compared to the untreated group (Group B) that developed marked lung metastasis, with a grade of $3.8 \pm 0.45(n=5)$.

\section{Bone formation induced by rhBMP-2 in tumor-bearing mice}

As shown in Figure 4A, three-dimensional (3D) reconstruction of tibia micro-architecture shows that the proximal tibia was completely eroded in the untreated groups (Groups A and B) at 42 days after inoculation with tumor cells. The impaired skeleton had deteriorated and developed structural failure at 56 days (Figure 4B). On the other hand, the integrity of the affected skeleton was much preserved with structured bone formation in Groups $\mathrm{C}$ and $\mathrm{D}$ that were treated with rhBMP-2 (Figure 4C and D).

In addition, as shown in Table 2, the defined image parameters used to assess bone quality were significantly higher in the treated group, including BV (Group $\mathrm{B}=3.35 \pm 0.19 \mathrm{~mm}^{3}$, Group $\mathrm{D}=5.26 \pm 1.75, P<0.05$ ), BMC (Group B $=3.38 \pm 0.22 \mathrm{mg}$, Group $\mathrm{D}=5.0 \pm 1.6, P<0.05$ ), and BS (Group B $=51.27 \pm 1.93 \mathrm{~mm}^{2}$, Group D $=73.5 \pm 20.78$, $P<0.05)$. Note that the assessed values of BV, BMC, and BS in Group D were even comparable to those in the normal control (Figure 5).

\section{Tumorigenicity and growth of OSA cells inhibited by rhBMP-2}

Immunohistochemical staining of the tumor sections confirmed that the growth of cells expressing a high level of aldehyde dehydrogenase (ALDH $\left.{ }^{\mathrm{br}}\right)$, a putative marker for a variety of cancer stem cells (CSCs), ${ }^{42,43}$ was suppressed in groups treated with rhBMP-2 compared to that in the 

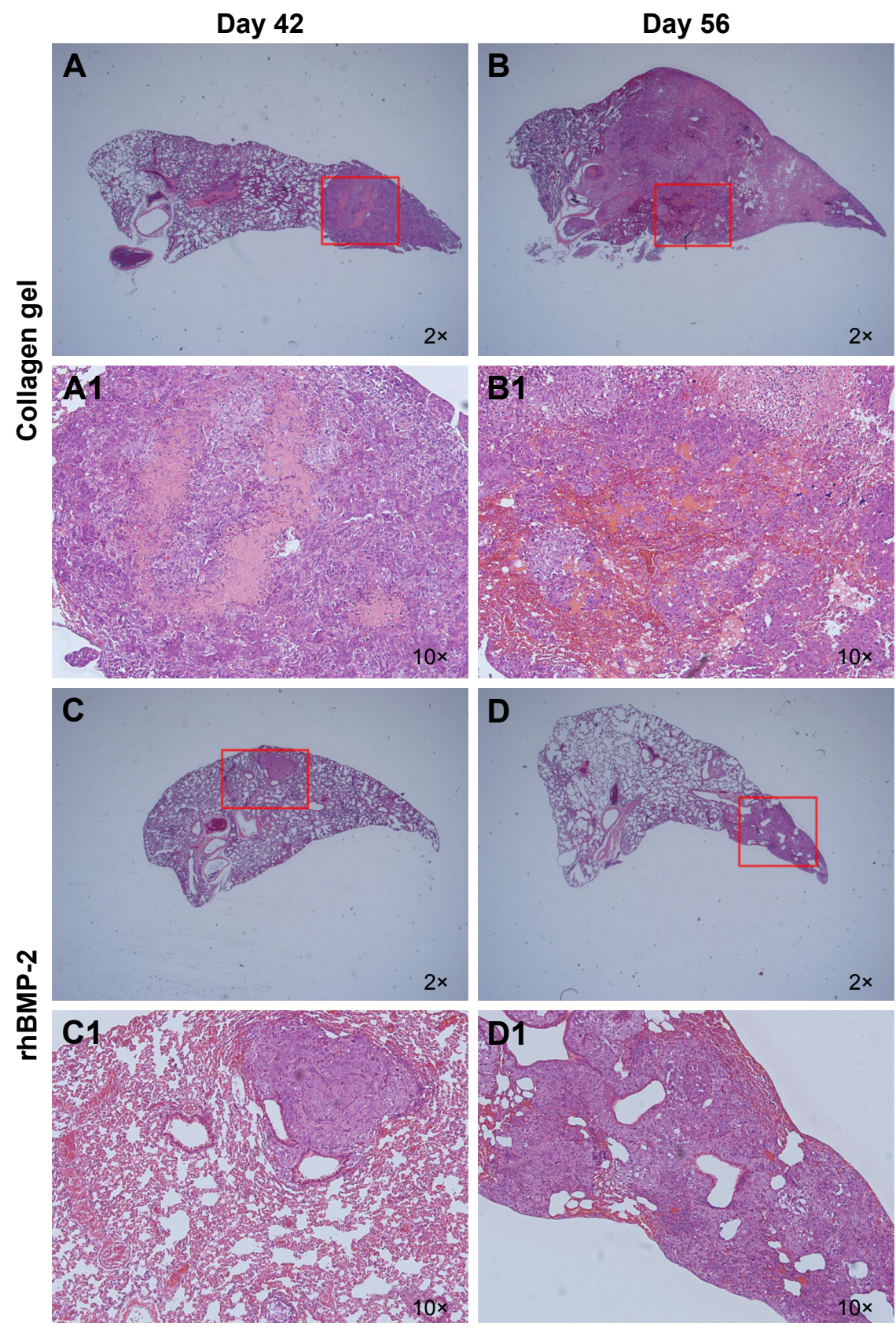

Figure 3 Histopathological appearance of lung metastasis nodules.

Notes: OSA tumor cells invaded into lung tissues and formed metastasis nodules in both of rhBMP-2 treated groups and the control. (A) Metastasis nodules were colonized in lung tissue in the gel control group at the 42 days. (B) Subsequently, metastasis nodules encroached the whole tissue confirmed by H\&E staining. (C) rhBMP-2 treated mice also developed metastasis nodules as found in the controls. (D) At 56 days, significantly less metastasis nodules were identified in the tumor-bearing mice treated with rhBMP-2. Nodules were clearly presented in the high magnification sections (AI-DI). Metastatic grades for each selected group, which is defined by the coverage of tumor cell aggregation, are $A=3, B=4, C=I$, and $D=2$. Relatively normal, $0 \%=0$; mild, $<25 \%=$ I; moderate, $25 \%-50 \%=2$; moderate to marked, $50 \%-75 \%=3 ;$ marked, $>75 \%=4$. Abbreviations: rhBMP-2, recombinant human BMP-2; OSA, osteosarcoma.

Table I Gradinga of lung metastasis of OSA-bearing animals

\begin{tabular}{l|l|l|l|l|l}
\hline Groups & Time $^{\mathrm{b}}$ & Drug & Metastasis grade & Mean \pm SD & Metastasis rate \\
\hline Group A & 42 days & Collagen gel & $\mathrm{I}, 2,2,3,4$ & $2.4 \pm I .14(\mathrm{n}=5)$ & $5 / 5$ \\
Group B & 56 days & Collagen gel & $3,4,4,4,4$ & $3.8 \pm 0.45(\mathrm{n}=5)$ & $5 / 5$ \\
Group C & 42 days & rhBMP-2 & $\mathrm{I}, \mathrm{I}, 2,3,3$ & $2.0 \pm 1.0(\mathrm{n}=5)$ & $5 / 5$ \\
Group D & 56 days & rhBMP-2 & $0,2,2,3,4$ & $2.2 \pm I .48(\mathrm{n}=5)$ & $4 / 5$ \\
\hline
\end{tabular}

Notes: a Grading criteria based on the coverage of tumor cell aggregation over the sectioned lung tissue. Relatively normal, $0 \%=0 ; \mathrm{mild},<25 \%=\mathrm{I} ; \mathrm{moderate}, 25 \%-50 \%=2$; moderate to marked, $50 \%-75 \%=3$; marked, $>75 \%=4$. ' $D a y s$ after the inoculation of human OSA $143 \mathrm{~B}$ cells.

Abbreviations: OSA, osteosarcoma; rhBMP-2, recombinant human BMP-2. 

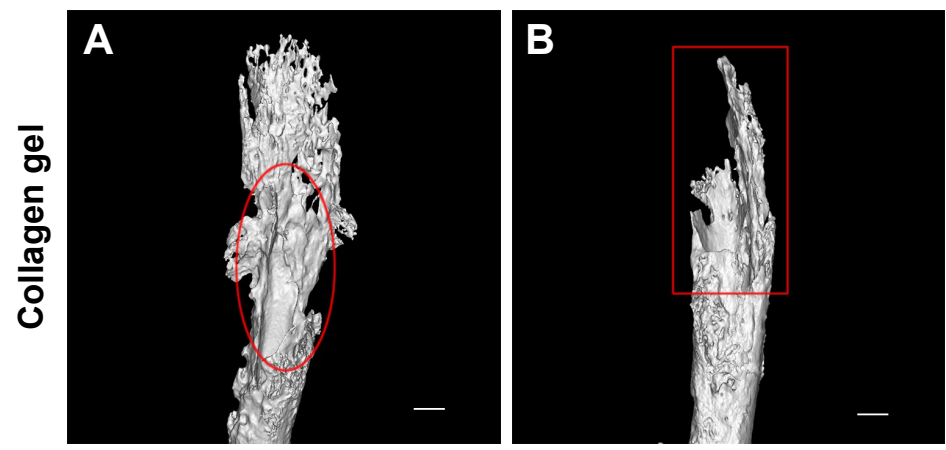

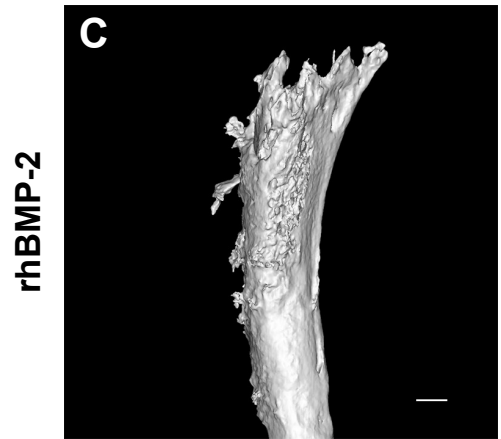

Day 42

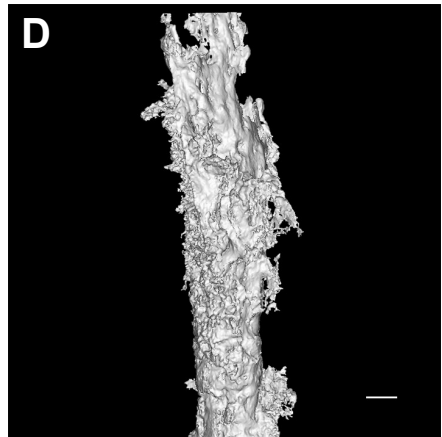

Day 56

Figure 4 rhBMP-2 reduced osteolysis and protected the integrity of the affected bone tissue.

Notes: (A) Three-dimensional reconstruction of tibia micro-architecture showed that proximal tibia was completely eroded in the untreated groups (red circle) at 42 days after inoculation with tumor cells. (B) The impaired skeleton was deteriorated and developed into structural failure at 56 days (red rectangle). On the other hand, the integrity of affected skeleton was much preserved (C), with the structured bone formation found in the groups treated with rhBMP-2 (D). Scale bar =I mm. Abbreviation: rhBMP-2, recombinant human BMP-2.

untreated ones (Figure 6). Ki-67-positive cells (highly proliferating cells) were also greatly reduced by BMP-2 treatment, whereas the expression of Ki-67 was much higher in Group C (untreated) at 42 days (Figure 7).

\section{Discussion}

OSA is the most common primary bone malignancy of childhood and adolescence, comprising almost $60 \%$ of the common histological subtypes of bone sarcomas in childhood. ${ }^{44}$ Despite the success of neoadjuvant chemotherapy for OSA to improve prognosis, OSA still has one of the lowest survival rates for pediatric cancer because of local recurrence and metastasis. Continuous efforts using immunotherapies, ${ }^{45,46}$ tissue factors, ${ }^{47}$ and/or surgical resections ${ }^{48}$ have been suggested to reduce lung metastasis; yet, the mechanisms of these strategies have not been fully elucidated. Increasing evidence supports the hypothesis that tumors are organized in a hierarchy of heterogeneous cell populations with different proliferative potentials. The capability to initiate tumor formation and promote tumor growth exclusively resides in a small subpopulation of tumor cells, termed CSCs or tumorinitiating cells. Many studies have confirmed that CSCs are responsible for tumor progression, metastasis, recurrence, and resistance to chemotherapy and radiation treatments. ${ }^{49-52}$ Experimental evidence also supports the notion that OSA are organized and sustained by CSCs. ${ }^{42,43,53,54}$

According to a maturation arrest model proposed by Sell, ${ }^{55,56}$ CSCs do not undergo typical turnover like mature

Table 2 Microstructural properties of the approached tibias analyzed by micro-computed tomography

\begin{tabular}{l|l|l|l|l|l|l}
\hline Groups & Time & Drug & vBMD $\left(\mathbf{m g} / \mathbf{m m}^{3}\right)$ & BV $\left.\mathbf{( m m}^{3}\right)$ & BMC $(\mathbf{m g})$ & BS $\left(\mathbf{m m}^{2}\right)$ \\
\hline Normal $^{\mathrm{a}}$ & 42 days & - & $0.93 \pm 0.01$ & $4.53 \pm 0.13$ & $4.22 \pm 0.17$ & $73.65 \pm 0.78$ \\
Normal & 56 days & - & $0.92 \pm 0.26$ & $4.84 \pm 0.45$ & $4.48 \pm 0.46$ & $77.83 \pm 6.59$ \\
Group A & 42 days & Collagen gel & $0.93 \pm 0.01$ & $4.02 \pm 0.21$ & $3.74 \pm 0.22$ & $64.3 \pm 0.52$ \\
Group B & 56 days & Collagen gel & $0.96 \pm 0.02$ & $3.53 \pm 0.19$ & $3.38 \pm 0.22$ & $51.27 \pm 1.93$ \\
Group C & 42 days & rhBMP-2 & $0.93 \pm 0.04$ & $4.06 \pm 0.4 I$ & $3.81 \pm 0.5$ & $57.04 \pm 1.91$ \\
Group D & 56 days & rhBMP-2 & $0.95 \pm 0.04$ & $5.26 \pm 1.75$ & $5.0 \pm 1.6$ & $73.5 \pm 20.78$ \\
\hline
\end{tabular}

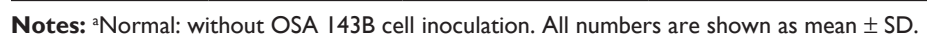

Abbreviations: vBMD, volumetric bone mineral density; BV, bone volume; BMC, bone mineral content; BS, bone surface; rhBMP-2, recombinant human BMP-2; OSA, osteosarcoma. 
A

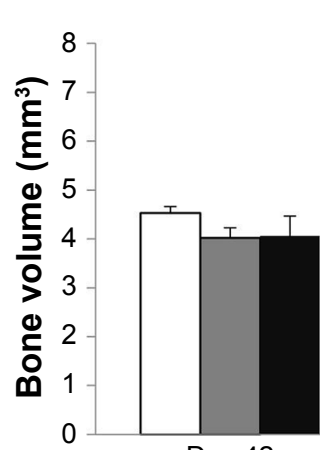

Day 42
B

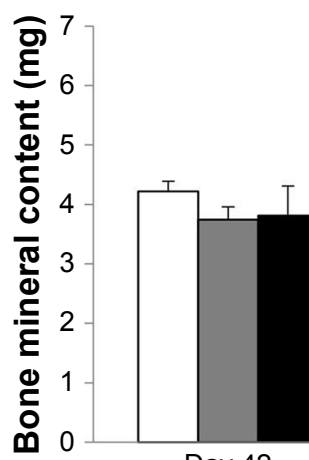

Day 42

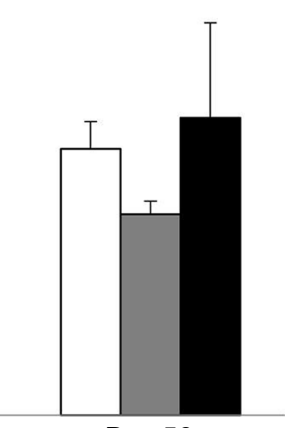

Day 56

C

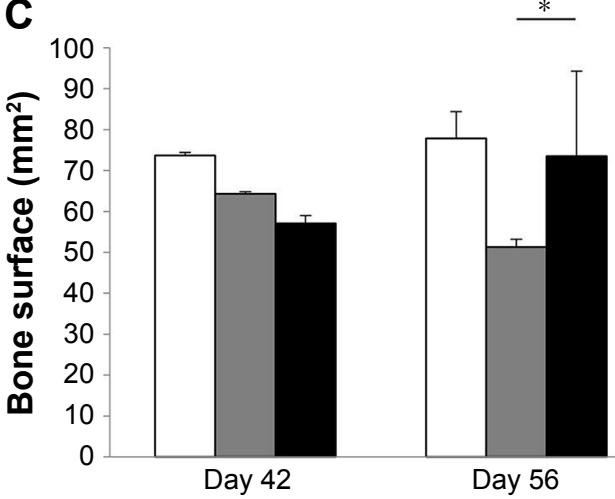

$\square$ Control $\square$ Collagen gel $\square$ rhBMP-2

Figure 5 Bone parameters increased by rhBMP-2.

Notes: $(\mathbf{A})$ Bone volume, $(\mathbf{B})$ bone mineral content and $(\mathbf{C})$ bone surface were significantly increased by rhBMP-2 compared with untreated groups after 56 days of cell inoculation $(n=8, * P<0.05)$.

Abbreviation: rhBMP-2, recombinant human BMP-2

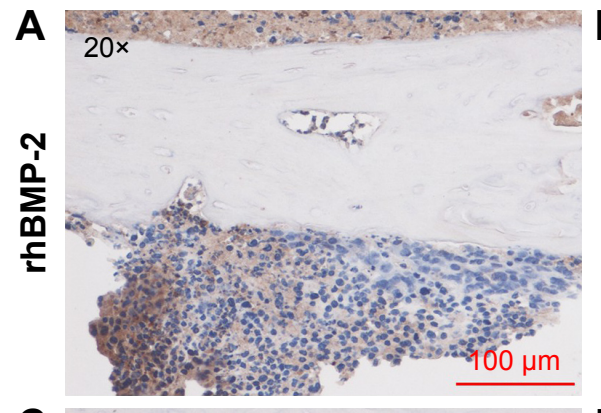

C $20 x$

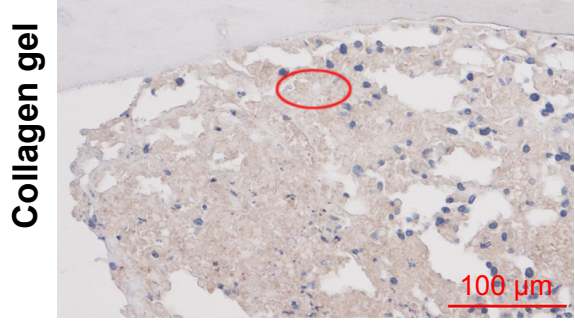

Day 42

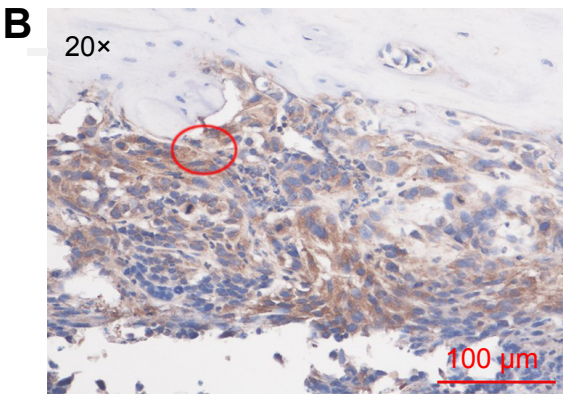

D

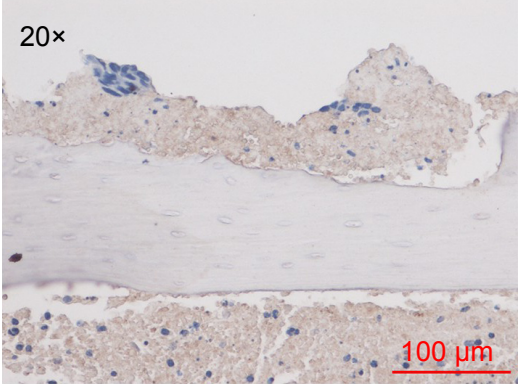

Day 56

Figure 6 Immunohistochemical staining of ALDH ${ }^{\text {br }}$ cells.

Notes: Growth of ALDH ${ }^{\text {br }}$ cells (red circles) were decreased at the injection site receiving rhBMP-2 treatment on day 42 (A) and 56 (B). On the contrary, ALDH ${ }^{\text {br }}$ cells remained dominant at the control sites treated with collagen gel both on day 42 (C) and 56 (D). Scale bar $=100 \mu \mathrm{m}$.

Abbreviations: rhBMP-2, recombinant human BMP-2; ALDH ${ }^{\text {br }}$, high aldehyde dehydrogenase expressed. 


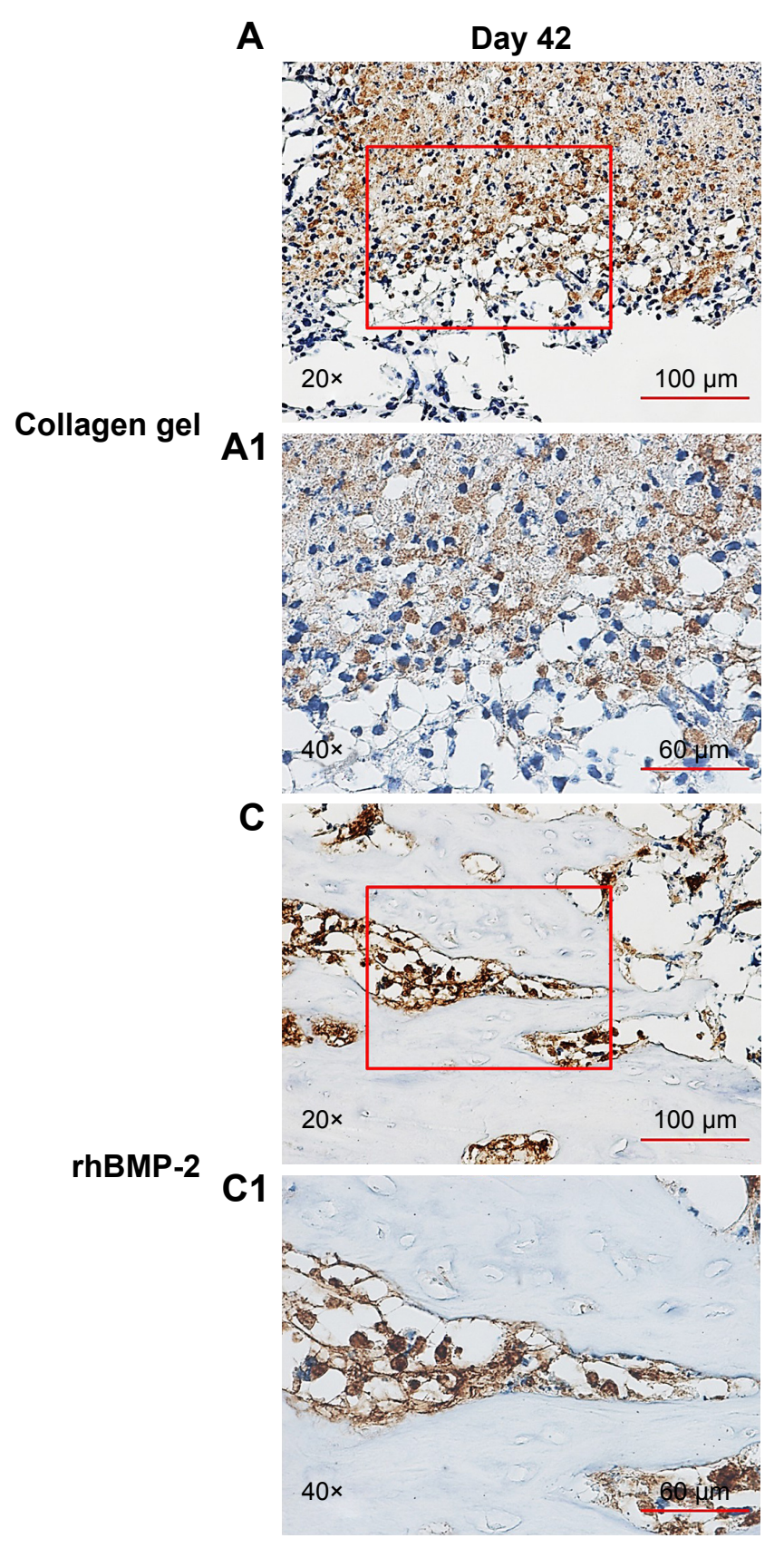

\section{B}

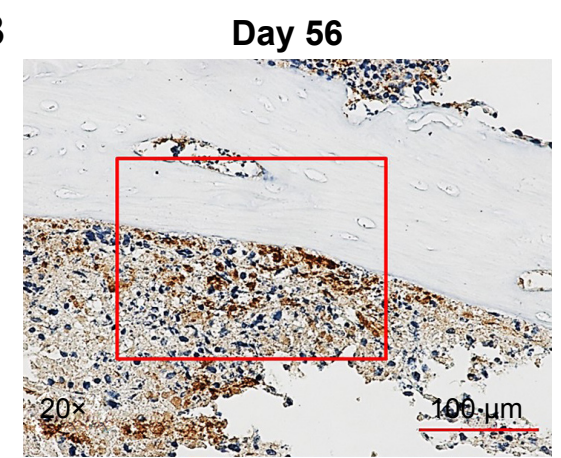

B1
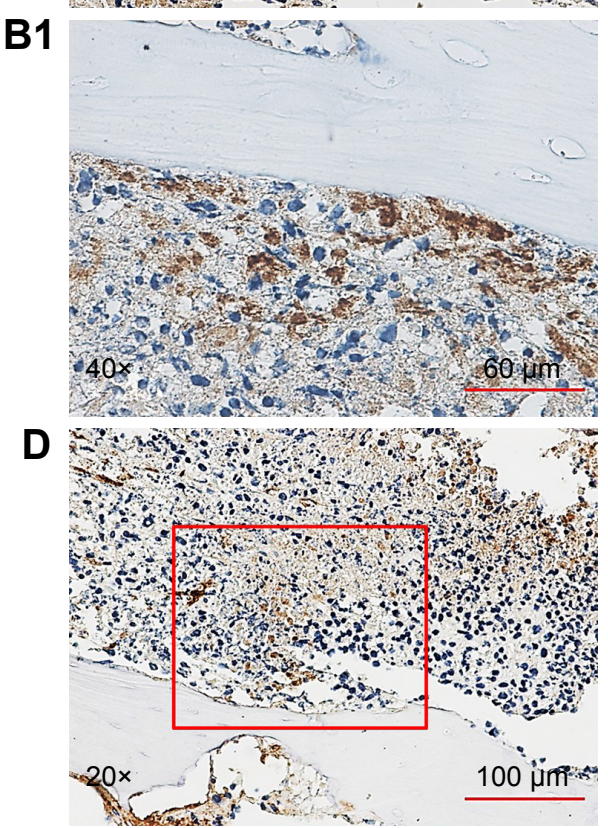

D1

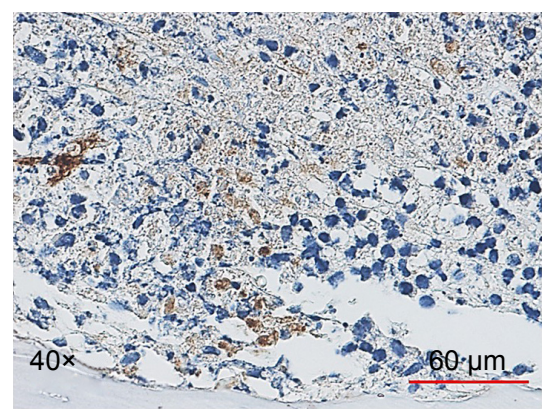

Figure 7 Reduction of Ki-67 positive cells by BMP-2 treatment.

Notes: Immunohistochemical staining shows expansion of $\mathrm{Ki}-67$ positive cells (brown stained) was unrestricted and became overwhelming in the collagen gel control groups (A and B). However, the expansion was then suppressed by the treated rhBMP-2 at the later time point (C and $\mathbf{D})$. Scale bar $=100 \mu \mathrm{m}$. Higher magnified regions of interest are indicated in AI-DI, with less spreading cells that are Ki-67 positive. Scale bar $=60 \mu \mathrm{m}$.

Abbreviation: rhBMP-2, recombinant human BMP-2.

cells and remain present before proliferative stimulus is given. This model also explains that the differentiation state of the cancer that develops will depend on the stage of differentiation at which maturation arrest occurs, thereby clarifying the cause of poor prognosis with lowly differentiated tumor cells. ${ }^{56}$ Differentiation therapy has been proposed to induce terminal differentiation of CSCs, thereby depriving CSCs of the selfrenewal property and chemoresistance. Extensive studies have shown that CSCs are chemoresistant until they are differentiated into amplifying "progenies", which become sensitive to chemotherapy ${ }^{57}$ In this aspect, differentiation therapy holds great promise for cancer treatment and has been supported by many studies. ${ }^{58-61}$ Yan et al confirmed that overexpression of IKKa induces differentiation and reduces tumorigenicity of nasopharyngeal carcinoma cells. ${ }^{62}$ Hepatocellular carcinoma (HCC)-derived CSCs could be differentiated into hepatocytes 
and neuronal cells by induction with the sex-determining factor. ${ }^{63}$ Other researchers also demonstrated that BMP-4 promotes differentiation of HCC-derived CSCs and in turn inhibits the self-renewal, chemotherapeutic resistance, and tumorigenic capacity of these cells. ${ }^{64} \mathrm{BMP}-4$ has also been reported to inhibit tumorigenic potential of human brain tumor-initiating cells. ${ }^{32}$ Campos et al revealed that all-trans retinoic acid (ATRA) induced differentiation of stem cell-like glioma cells, leading to reduced motility and tumorigenicity of CSCs in vitro. ${ }^{65}$ ATRA treatment was also found to be effective to induce differentiation of breast cancer cells, resulting in reduced invasiveness and migration, and increased sensitivity to anticancer treatment. ${ }^{66}$ Wang et al suggested that CSCs in OSA can be induced by BMP-2 toward osteogenic differentiation that in turn drastically restricts their tumorigenecity, $37,42,43,67$ thereby supporting the early concept to introduce BMP-2 as a differentiation therapy for treating OSA.

In the present study, we aimed to use an orthotopic model to further our investigation of the proposed differentiation therapy with BMP-2 that restricts lung metastasis. A high tumor formation rate and pulmonary metastasis were noted to be associated with the developed model. This was very beneficial for assessing the efficacies of new therapeutics to treat OSA as the model replicates the critical symptoms of the tumor as well as exhibits a high incidence of tumor occurrence. However, as reported earlier, there was spontaneous death occurring within 40 days. The short survival time of tumor-bearing animals can be attributed to high concentration of the injected tumor cells as indicated elsewhere. ${ }^{41}$

As shown histopathologically, the metastatic tumor in lung tissues was suppressed in the rhBMP-2-treated animals for a longer period of time compared to that in the untreated groups. In a similar study reported by Gill et al, the authors concluded that when treated with BMP-2, either single dose or multiple doses, there was no difference in the incidence of lung metastasis in animals developing OSA; this finding was consistent with our observation in the present study. ${ }^{40}$

In addition, our results also showed that BV and BMC, the most indicational parameters of bone quantity, were significantly increased in the tumor-bearing animals treated with rhBMP-2 at 56 days. This was consistent with the rendered, reconstructed $3 \mathrm{D}$ images of the approached tibiae, where non-diffuse new bone formation was observed in the treatment groups. In contrast, large and extensive bone defects were found in the untreated groups. These results suggest that the treatment with rhBMP-2 induced bone formation in the OSA-impaired skeleton, which helps to preserve the integrity of the affected bone tissue in the tumor-bearing mice, thus suggesting a bone protective effect of the investigated regimen for the tumor-affected bone tissue.

Our data also showed that $\mathrm{ALDH}^{\text {br }}$ cells ${ }^{42,43}$ and $\mathrm{Ki}-67-$ positive cells were decreased with the treatment, indicating that the tumor expansion was restricted by rhBMP-2. However, it was noted that Ki-67-positive cells were still highly present at the early stage during the treatment. This phenomenon corresponds to the Sell's model of maturation arrest, in which the more differentiated progenies of CSCs undergo an amplifying stage to expand the tumor and maintain its heterogenicity. ${ }^{55,56}$ With the delivered rhBMP-2 in the vicinity, these cells became more differentiated and fate-determined with downregulated ALDH expression and proliferative capacity. These results were consistent with the findings reported by Wang et al wherein CSCs and their low aldehyde dehydrogenase-expressing progenies were induced to form calcified and structured bone tissue with much restricted proliferating cells. ${ }^{37,42,43,67,68}$

Although the current study additionally presents an encouraging promise to incorporate BMP-2 and/or its analogies into the current regimens to treat OSA, further investigations are necessary to elucidate the proposed mechanism. First, as the early data presented in this study show a tendency for rhBMP-2 to suppress lung metastasis of OSA, it will be more clinically meaningful to see how this correlates with the survival rate of the recruited animals. Second, previous studies have shown that the expression of key CSC markers such as Oct3/4a, Nanog, and Sox-2 genes is downregulated with elevated expression of osteogenic markers such as Runx-2, ALP, and collagen type I both in vitro and in vivo (subcutaneously) when the OSA cells are exposed to rhBMP-2. ${ }^{37,43,67}$ Given the complexity of the bone microenvironment in situ, it certainly warrants more detailed studies by recovering cells from the affected skeleton of the animals for molecular probing. We believe that this will help to understand how the cells might follow the proposed pathways to respond to BMP-2 treatment as reported previously. ${ }^{37,42,67}$ Last, it is also of our interest to perform biomechanical testing of the affected limb to assess the level of functional preservation of the affected bone tissue, such as its mechanical strength and material properties.

\section{Acknowledgments}

The authors acknowledge all the participants and participating institutes for experimental and technical support in this study. The present study was supported by the National Natural Science Foundation of China (NSFC grant no 31470045). 


\section{Disclosure}

The authors report no conflicts of interest in this work.

\section{References}

1. Picci P. Osteosarcoma: What did we learn from the paediatric experience for adolescents and young adults? European Journal of Cancer Supplements. 2007;5(5):227-234.

2. Sweetnam R. Osteosarcoma. Br J Hosp Med. 1982;28(2):112, $116-121$.

3. Dorfman HD, Czerniak B. Bone cancers. Cancer. 1995;75(1 Suppl): 203-210.

4. Ottaviani G, Jaffe N. The epidemiology of osteosarcoma. Cancer Treat Res. 2009;152:3-13.

5. Mirabello L, Troisi RJ, Savage SA. Osteosarcoma incidence and survival rates from 1973 to 2004: data from the Surveillance, Epidemiology, and End Results Program. Cancer. 2009;115(7):1531-1543.

6. Wang LL. Biology of osteogenic sarcoma. Cancer J. 2005;11(4): 294-305.

7. Ek ET, Ojaimi J, Kitagawa Y, Choong PF. Outcome of patients with osteosarcoma over 40 years of age: is angiogenesis a marker of survival? Int Semin Surg Oncol. 2006;3:7.

8. Huvos AG. Osteogenic sarcoma of bones and soft tissues in older persons. A clinicopathologic analysis of 117 patients older than 60 years. Cancer. 1986;57(7):1442-1449.

9. Meyers PA, Schwartz CL, Krailo MD, et al. Osteosarcoma: the addition of muramyl tripeptide to chemotherapy improves overall survival - a report from the Children's Oncology Group. J Clin Oncol. 2008;26(4):633-638.

10. Damron TA, Ward WG, Stewart A. Osteosarcoma, chondrosarcoma, and Ewing's sarcoma: National Cancer Data Base Report. Clin Orthop Relat Res. 2007;459:40-47.

11. Kager L, Zoubek A, Pötschger U, et al. Primary metastatic osteosarcoma: presentation and outcome of patients treated on neoadjuvant Cooperative Osteosarcoma Study Group protocols. J Clin Oncol. 2003; 21(10):2011-2018.

12. Mintz MB, Sowers R, Brown KM, et al. An expression signature classifies chemotherapy-resistant pediatric osteosarcoma. Cancer Res. 2005; 65(5):65-1754.

13. Endo-Munoz L, Cumming A, Sommerville S, Dickinson I, Saunders NA. Osteosarcoma is characterised by reduced expression of markers of osteoclastogenesis and antigen presentation compared with normal bone. Br J Cancer. 2010;103(1):73-81.

14. Haydon RC, Zhou L, Feng T, et al. Nuclear receptor agonists as potential differentiation therapy agents for human osteosarcoma. Clin Cancer Res. 2002;8(5):1288-1294.

15. Chou AJ, Gorlick R. Chemotherapy resistance in osteosarcoma: current challenges and future directions. Expert Rev Anticancer Ther. 2006;6(7): 1075-1085.

16. Clark JC, Dass CR, Choong PF. A review of clinical and molecular prognostic factors in osteosarcoma. J Cancer Res Clin Oncol. 2008; 134(3):281-297.

17. Janeway KA, Grier HE. Sequelae of osteosarcoma medical therapy: a review of rare acute toxicities and late effects. Lancet Oncol. 2010; 1(7):670-678.

18. Wozney JM, Rosen V, Celeste AJ, et al. Novel regulators of bone formation: molecular clones and activities. Science. 1988;242(4885): $1528-1534$.

19. Chen G, Deng C, Li YP, Yp L. TGF- $\beta$ and BMP signaling in osteoblast differentiation and bone formation. Int J Biol Sci. 2012;8(2): 272-288.

20. Ye L, Mason MD, Jiang WG. Bone morphogenetic protein and bone metastasis, implication and therapeutic potential. Front Biosci. 2011; 16:865.

21. Hruska KA, Mathew S, Saab G. Bone morphogenetic proteins in vascular calcification. Circ Res. 2005;97(2):105-114.

22. Hogan BL. Bone morphogenetic proteins: multifunctional regulators of vertebrate development. Genes Dev. 1996;10(13):1580-1594.
23. Barboza E, Caúla A, Machado F. Potential of recombinant human bone morphogenetic protein-2 in bone regeneration. Implant Dent. 1999; 8(4):360-367.

24. Thawani JP, Wang AC, Than KD, Lin CY, La Marca F, Park P. Bone morphogenetic proteins and cancer: review of the literature. Neurosurgery. 2010;66(2):233-246.

25. Kleeff J, Maruyama H, Ishiwata T, et al. Bone morphogenetic protein 2 exerts diverse effects on cell growth in vitro and is expressed in human pancreatic cancer in vivo. Gastroenterology. 1999;116(5):1202-1216.

26. Langenfeld EM, Calvano SE, Abou-Nukta F, Lowry SF, Amenta P, Langenfeld $\mathrm{J}$. The mature bone morphogenetic protein-2 is aberrantly expressed in non-small cell lung carcinomas and stimulates tumor growth of A549 cells. Carcinogenesis. 2003;24(9):1445-1454.

27. Ghosh-Choudhury N, Woodruff K, Qi W, Celeste A, Abboud SL, Ghosh Choudhury G. Bone morphogenetic protein-2 blocks MDA MB 231 human breast cancer cell proliferation by inhibiting cyclin-dependent kinase-mediated retinoblastoma protein phosphorylation. Biochem Biophys Res Commun. 2000;272(3):705-711.

28. Ghosh-Choudhury N, Ghosh-Choudhury G, Celeste A, et al. Bone morphogenetic protein-2 induces cyclin kinase inhibitor $\mathrm{p} 21$ and hypophosphorylation of retinoblastoma protein in estradiol-treated MCF-7 human breast cancer cells. Biochim Biophys Acta. 2000;1497(2):186-196.

29. Kawamura C, Kizaki M, Yamato K, et al. Bone morphogenetic protein-2 induces apoptosis in human myeloma cells with modulation of STAT3. Blood. 2000;96(6):2005-2011.

30. Wen XZ, Miyake S, Akiyama Y, Yuasa Y. BMP-2 modulates the proliferation and differentiation of normal and cancerous gastric cells. Biochem Biophys Res Commun. 2004;316(1):100-106.

31. Beck SE, Jung BH, Fiorino A, et al. Bone morphogenetic protein signaling and growth suppression in colon cancer. Am J Physiol Gastrointest Liver Physiol. 2006;291(1):G135-G145.

32. Piccirillo SG, Reynolds BA, Zanetti N, et al. Bone morphogenetic proteins inhibit the tumorigenic potential of human brain tumourinitiating cells. Nature. 2006;444(7120):761-765.

33. Ide H, Yoshida $\mathrm{T}$, Matsumoto N, et al. Growth regulation of human prostate cancer cells by bone morphogenetic protein-2. Cancer Res. 1997; 57(22):5022-5027.

34. Brubaker KD, Corey E, Brown LG, Vessella RL. Bone morphogenetic protein signaling in prostate cancer cell lines. J Cell Biochem. 2004; 91(1):151-160.

35. Huang W, Rudkin GH, Carlsen B, et al. Overexpression of BMP-2 modulates morphology, growth, and gene expression in osteoblastic cells. Exp Cell Res. 2002;274(2):226-234.

36. Geng S, Sun B, Lu R, Wang J. Coleusin factor, a novel anticancer diterpenoid, inhibits osteosarcoma growth by inducing bone morphogenetic protein-2-dependent differentiation. Mol Cancer Ther. 2014;13(6): $1431-1441$.

37. Wang L, Park P, Zhang H, et al. BMP-2 inhibits the tumorigenicity of cancer stem cells in human osteosarcoma OS99-1 cell line. Cancer Biol Ther. 2011;11(5):457-463.

38. Wang L, Park P, Zhang H, et al. BMP-2 inhibits tumor growth of human renal cell carcinoma and induces bone formation. Int $J$ Cancer. 2012;131(8):1941-1950.

39. Geller DS, Singh MY, Zhang W, et al. Development of a model system to evaluate local recurrence in osteosarcoma and assessment of the effects of bone morphogenetic protein-2. Clin Cancer Res. 2015;21(13): 3003-3012.

40. Gill J, Connolly P, Roth M, et al. The effect of bone morphogenetic protein-2 on osteosarcoma metastasis. PLoS One. 2017;12(3):e0173322.

41. Yu Z, Sun H, Fan Q, Long H, Yang T, Ma B. Establishment of reproducible osteosarcoma rat model using orthotopic implantation technique. Oncol Rep. 2009;21(5):1175-1180.

42. Wang L, Park P, Zhang H, La Marca F, Lin CY. Prospective identification of tumorigenic osteosarcoma cancer stem cells in OS99-1 cells based on high aldehyde dehydrogenase activity. Int J Cancer. 2011; 128(2):294-303.

43. Wang L, Park P, Lin CY. Characterization of stem cell attributes in human osteosarcoma cell lines. Cancer Biol Ther. 2009;8(6):543-552. 
44. Gatta G, Capocaccia R, Stiller C, et al. Childhood cancer survival trends in Europe: a EUROCARE Working Group study. J Clin Oncol. 2005;23(16):3742-3751.

45. Shimizu T, Fuchimoto Y, Fukuda K, Okita H, Kitagawa Y, Kuroda T. The effect of immune checkpoint inhibitors on lung metastases of osteosarcoma. J Pediatr Surg. 2017;52(12):2047-2050.

46. Saraf AJ, Fenger JM, Roberts RD. Osteosarcoma: Accelerating Progress Makes for a Hopeful Future. Front Oncol. 2018;8:4.

47. Tieken C, Verboom MC, Ruf W, et al. Tissue factor associates with survival and regulates tumour progression in osteosarcoma. Thromb Haemost. 2016;115(5):1025-1033.

48. Heaton TE, Davidoff AM. Surgical treatment of pulmonary metastases in pediatric solid tumors. Semin Pediatr Surg. 2016;25(5):311-317.

49. Pardal R, Clarke MF, Morrison SJ. Applying the principles of stem-cell biology to cancer. Nat Rev Cancer. 2003;3(12):895-902.

50. Jordan CT, Guzman ML, Noble M. Cancer stem cells. N Engl J Med. 2006;355(12):1253-1261.

51. Clarke MF, Dick JE, Dirks PB, et al. Cancer stem cells - perspectives on current status and future directions: AACR Workshop on cancer stem cells. Cancer Res. 2006;66(19):9339-9344.

52. Dean M, Fojo T, Bates S. Tumour stem cells and drug resistance. Nat Rev Cancer. 2005;5(4):275-284.

53. Basu-Roy U, Basilico C, Mansukhani A. Perspectives on cancer stem cells in osteosarcoma. Cancer Lett. 2013;338(1):158-167.

54. Abarrategi A, Tornin J, Martinez-Cruzado L, et al. Osteosarcoma: Cellsof-Origin, Cancer Stem Cells, and Targeted Therapies. Stem Cells Int. 2016;2016:13-13.

55. Sell S. Stem cell origin of cancer and differentiation therapy. Crit Rev Oncol Hematol. 2004;51(1):1-28.

56. Sell S. Cancer stem cells and differentiation therapy. Tumour Biol. 2006;27(2):59-70.

57. Abdullah LN, Chow EK. Mechanisms of chemoresistance in cancer stem cells. Clin Transl Med. 2013;2(1):3-3.
58. Massard C, Deutsch E, Soria JC. Tumour stem cell-targeted treatment: elimination or differentiation. Ann Oncol. 2006;17(11):1620-1624.

59. Aguado T, Carracedo A, Julien B, et al. Cannabinoids induce glioma stem-like cell differentiation and inhibit gliomagenesis. J Biol Chem 2007;282(9):6854-6862.

60. Yan M, Liu Q. Differentiation therapy: a promising strategy for cancer treatment. Chin J Cancer. 2016;35:3.

61. Jin X, Jin X, Kim H. Cancer stem cells and differentiation therapy. Tumour Biol. 2017;39(10):1010428317729933.

62. Yan $\mathrm{M}$, Zhang Y, He B, et al. IKK $\alpha$ restoration via EZH2 suppression induces nasopharyngeal carcinoma differentiation. Nat Commun. 2014;5:3661.

63. Murakami S, Ninomiya W, Sakamoto E, Shibata T, Akiyama H, Tashiro F. SRY and OCT4 Are Required for the Acquisition of Cancer Stem CellLike Properties and Are Potential Differentiation Therapy Targets. Stem Cells. 2015;33(9):2652-2663.

64. Zhang L, Sun H, Zhao F, et al. BMP4 administration induces differentiation of CD133+ hepatic cancer stem cells, blocking their contributions to hepatocellular carcinoma. Cancer Res. 2012;72(16):4276-4285.

65. Campos B, Wan F, Farhadi M, et al. Differentiation therapy exerts antitumor effects on stem-like glioma cells. Clin Cancer Res. 2010; 16(10):2715-2728.

66. Yan Y, Li Z, Xu X, et al. All-trans retinoic acids induce differentiation and sensitize a radioresistant breast cancer cells to chemotherapy. BMC Complement Altern Med. 2016;16:113.

67. Wang L, Park P, La Marca F, Than K, Rahman S, Lin CY. Bone formation induced by BMP-2 in human osteosarcoma cells. Int J Oncol. 2013;43(4):1095-1102.

68. Wang L, Park P, La Marca F, Than KD, Lin CY. BMP-2 inhibits tumor-initiating ability in human renal cancer stem cells and induces bone formation. J Cancer Res Clin Oncol. 2015;141(6):1013-1024.
OncoTargets and Therapy

\section{Publish your work in this journal}

OncoTargets and Therapy is an international, peer-reviewed, open access journal focusing on the pathological basis of all cancers, potential targets for therapy and treatment protocols employed to improve the management of cancer patients. The journal also focuses on the impact of management programs and new therapeutic agents and protocols on

\section{Dovepress}

patient perspectives such as quality of life, adherence and satisfaction. The manuscript management system is completely online and includes a very quick and fair peer-review system, which is all easy to use. Visit http://www.dovepress.com/testimonials.php to read real quotes from published authors. 